\title{
Draft Manuscript
}

\section{Transient Three-Dimensional Side Load Analysis of a Film Cooled Nozzle}

\author{
Ten-See Wang*, Mike Guidos \\ NASA Marshall Space Flight Center, Huntsville, Alabama, 35812
}

\begin{abstract}
Transient three-dimensional numerical investigations on the side load physics for an engine encompassing a film cooled nozzle extension and a regeneratively cooled thrust chamber, were performed. The objectives of this study are to identify the three-dimensional side load physics and to compute the associated aerodynamic side load using an anchored computational methodology. The computational methodology is based on an unstructuredgrid, pressure-based computational fluid dynamics formulation, and a transient inlet history based on an engine system simulation. Ultimately, the computational results will be provided to the nozzle designers for estimating of effect of the peak side load on the nozzle structure. Computations simulating engine startup at ambient pressures corresponding to sea level and three high altitudes were performed. In addition, computations for both engine startup and shutdown transients were also performed for a stub nozzle, operating at sea level. For engine with the full nozzle extension, computational result shows starting up at sea level, the peak side load occurs when the lambda shock steps into the turbine exhaust flow, while the side load caused by the transition from free-shock separation to restricted-shock separation comes at second; and the side loads decreasing rapidly and progressively as the ambient pressure decreases. For the stub nozzle operating at sea level, the computed side loads during both startup and shutdown becomes very small due to the much reduced flow area.
\end{abstract}

\footnotetext{
"Technical Assistant, ER43, Thermal and Combustion Analysis Branch, Propulsion Structure, Thermal, and Fluids Analysis Division, Senior Member AIAA.
} 


\section{Nomenclature}

$C_{1}, C_{2}, C_{3}, C_{\mu}=$ turbulence modeling constants, $1.15,1.9,0.25$, and 0.09 .

$C_{p} \quad=$ heat capacity

D = diffusivity

$H \quad=$ total enthalpy

$I \quad=$ radiative intensity

$K \quad=$ thermal conductivity

$k \quad=$ turbulent kinetic energy

p $\quad$ pressure

$Q \quad=$ heat flux

$R \quad$ = recovery factor

$r \quad=$ location coordinate

$T \quad=$ temperature

$T^{+} \quad=$ non-dimensional temperature

$t \quad=$ time, $\mathrm{s}$

$u_{i} \quad=$ mean velocities in three directions

$u_{\tau} \quad=$ wall friction velocity

$x=$ Cartesian coordinates

$\varepsilon \quad=$ turbulent kinetic energy dissipation rate

$\theta \quad=$ energy dissipation contribution

$\kappa \quad=$ absorption coefficient

$\mu \quad=$ viscosity

$\mu_{i} \quad=$ turbulent eddy viscosity $\left(=\rho \mathrm{C}_{\mu} \mathrm{k}^{2} / \varepsilon\right)$

$\Pi \quad=$ turbulent kinetic energy production

$\rho \quad=$ density

$\sigma \quad=$ turbulence modeling constants

$\tau \quad=$ shear stress 


\section{Subscripts \\ $c \quad=$ convective \\ $t \quad=$ turbulent flow}

\section{Introduction}

Structural damages caused by the side load to nozzle components have been found for almost every rocket engine during development, including damages to past engines in development such as those in the $J 2$ engine, ${ }^{1}$ Block-I Space Shuttle Main Engine (SSME), ${ }^{\mathrm{Cl}}$ and recently, the Fastrac Engine, ${ }^{\mathrm{B} 1}$ and more recently, those in the European Vulcain engine $^{2}$ and the Japanese LE-7A engine. ${ }^{3}$ As such, nozzle side load has been recognized as a high risk item during engine development, and many an efforts have been devoted to the understanding of nozzle physics and subsequently, to the development of methodologies that predict peak side load accurately to help design engineers designing structures that could withstand the side forces.

The slanted plane method has been used by designers to produce peak side load estimates, by assuming a slanted plane with one end touches the nozzle lip, and with another end touches somewhere on the nozzle inside wall. That forms an asymmetric flow and a side force can be estimated. The slanted plane however is highly empirical. It requires empirical data to establish its parameters. When a new nozzle design comes up and its design and operating parameters out of the experience base, then the slanted plane method is difficult to use since it is not entirely based cn the physics and not a predictive method.

With the advances of computers and computational methods, three-dimensional, time-accurate computational methodologies have been developed to closely simulate the side load physics and therefore showing the potential to predict the side load. Koichi simulated the transition of free-shock separation (FSS) to restricted-shock separation (RSS) for Japanese's LE-7A engine. Luca simulated a turbine exhaust gas cooled nozzle flow. In USA, Wang developed a methodology that benchmarked with the startup transient of the Space Shuttle Main Engine (SSME). This methodology addresses two important side load drivers; the combustion and the histories of pressure ramping and propellant valve sequencing. Not only the shock transition was simulated, but also the shock oscillation at the 
lip was simulated for the first time. More importantly, the predicted peak and secondary side loads agreed reasonably well with those of test data.

In this work, the same computational methodology was used to simulate the startup transients for a preliminary version of the $\mathrm{J} 2-\mathrm{X}$ nozzle design during hot-fire testing for ambient pressures at sea level and at three different altitudes. In addition, bother startup and shutdown transients were simulated for a stub nozzle at sea level to see if the peak side load is reduced than that with the full nozzle extension. The computed nozzle side load physics are discussed and the computed peak nozzle side loads are compared with available test data.

\section{Computational Methodology}

\section{A. Computational Fluid Dynamics}

The CFD methodology is based on a multi-dimensional, finite-volume, viscous, chemically reacting, unstructured grid, and pressure-based formulation. Time-varying transport equations of continuity, species continuity , momentum, total enthalpy, turbulent kinetic energy, and turbulent kinetic energy dissipation were solved using a time-marching sub-iteration scheme and are written as:

$$
\begin{aligned}
& \frac{\partial \rho}{\partial t}+\frac{\partial}{\partial x_{j}}\left(\rho u_{j}\right)=0 \\
& \frac{\partial \rho \alpha_{i}}{\partial t}+\frac{\partial}{\partial x_{j}}\left(\rho u_{j} \alpha_{i}\right)=\frac{\partial}{\partial x_{j}}\left[\left(\rho D+\frac{\mu_{t}}{\sigma_{\alpha}}\right) \frac{\partial \alpha_{i}}{\partial x_{j}}\right]+\omega_{i}
\end{aligned}
$$




$$
\begin{aligned}
& \frac{\partial \rho u_{i}}{\partial t}+\frac{\partial}{\partial x_{j}}\left(\rho u_{j} u_{i}\right)=-\frac{\partial p}{\partial x_{i}}+\frac{\partial \tau_{i j}}{\partial x_{j}} \\
& \frac{\partial \rho H}{\partial t}+\frac{\partial}{\partial x_{j}}\left(\rho u_{j} H\right)=\frac{\partial p}{\partial t}+Q_{r}+\frac{\partial}{\partial x_{j}}\left(\left(\frac{K}{C_{p}}+\frac{\mu_{t}}{\sigma_{H}}\right) \nabla H\right)+\frac{\partial}{\partial x_{j}}\left(\left(\left(\mu+\mu_{t}\right)-\left(\frac{K}{C_{p}}+\frac{\mu_{t}}{\sigma_{H}}\right)\right) \nabla\left(V^{2} / 2\right)\right)+\theta \\
& \frac{\partial \rho k}{\partial t}+\frac{\partial}{\partial x_{j}}\left(\rho u_{j} k\right)=\frac{\partial}{\partial x_{j}}\left[\left(\mu+\frac{\mu_{t}}{\sigma_{k}}\right) \frac{\partial k}{\partial x_{j}}\right]+\rho(\Pi-\varepsilon) \\
& \frac{\partial \rho \varepsilon}{\partial t}+\frac{\partial}{\partial x_{j}}\left(\rho u_{j} \varepsilon\right)=\frac{\partial}{\partial x_{j}}\left[\left(\mu+\frac{\mu_{t}}{\sigma_{\varepsilon}}\right) \frac{\partial \varepsilon}{\partial x_{j}}\right]+\rho \frac{\varepsilon}{k}\left(C_{1} \Pi-C_{2} \varepsilon+C_{3} \Pi^{2} / \varepsilon\right)
\end{aligned}
$$
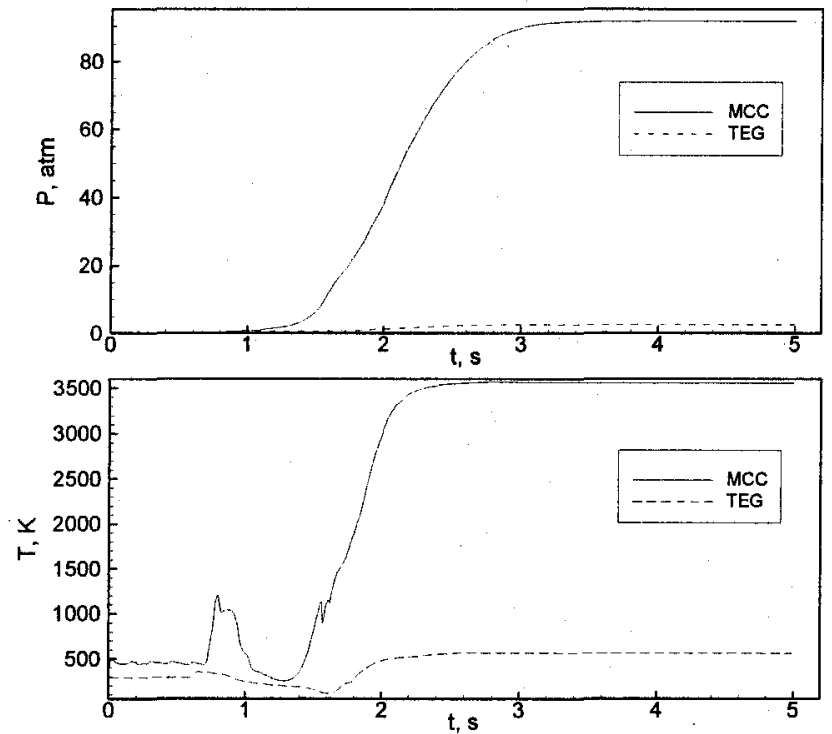

Fig. 1 Simulated inlet pressure and temperature histories for the main combustion chamber and turbine exhaust gas flows during the start-up transient.
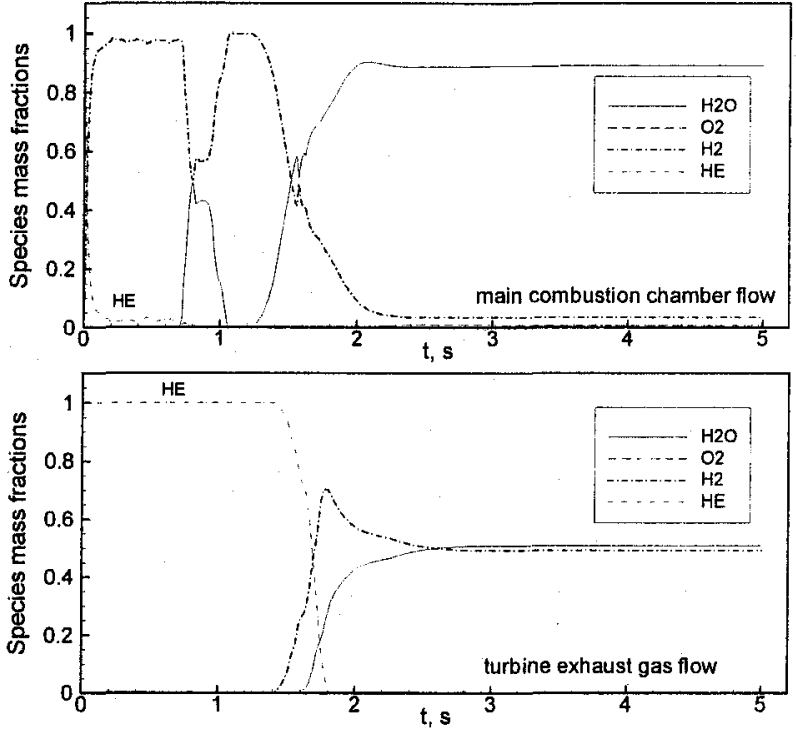

Fig. 2 Simulated inlet species mass fraction histories for the main combustion chamber and turbine exhaust gas flows during the start-up transient.

A predictor and corrector solution algorithm was

employed to provide coupling of the governing equations. A second-order central-difference scheme was employed to discretize the diffusion fluxes and source terms. For the convective terms, a second-order upwind total variation diminishing difference scheme was used. To enhance the temporal accuracy, a second-order backward difference scheme was employed to discretize the temporal terms. Details of the numerical algorithm can be found in Ref's 912. 
An extended k- $\varepsilon$ turbulence model ${ }^{13}$ was used to describe the turbulence. A modified wall function approach was
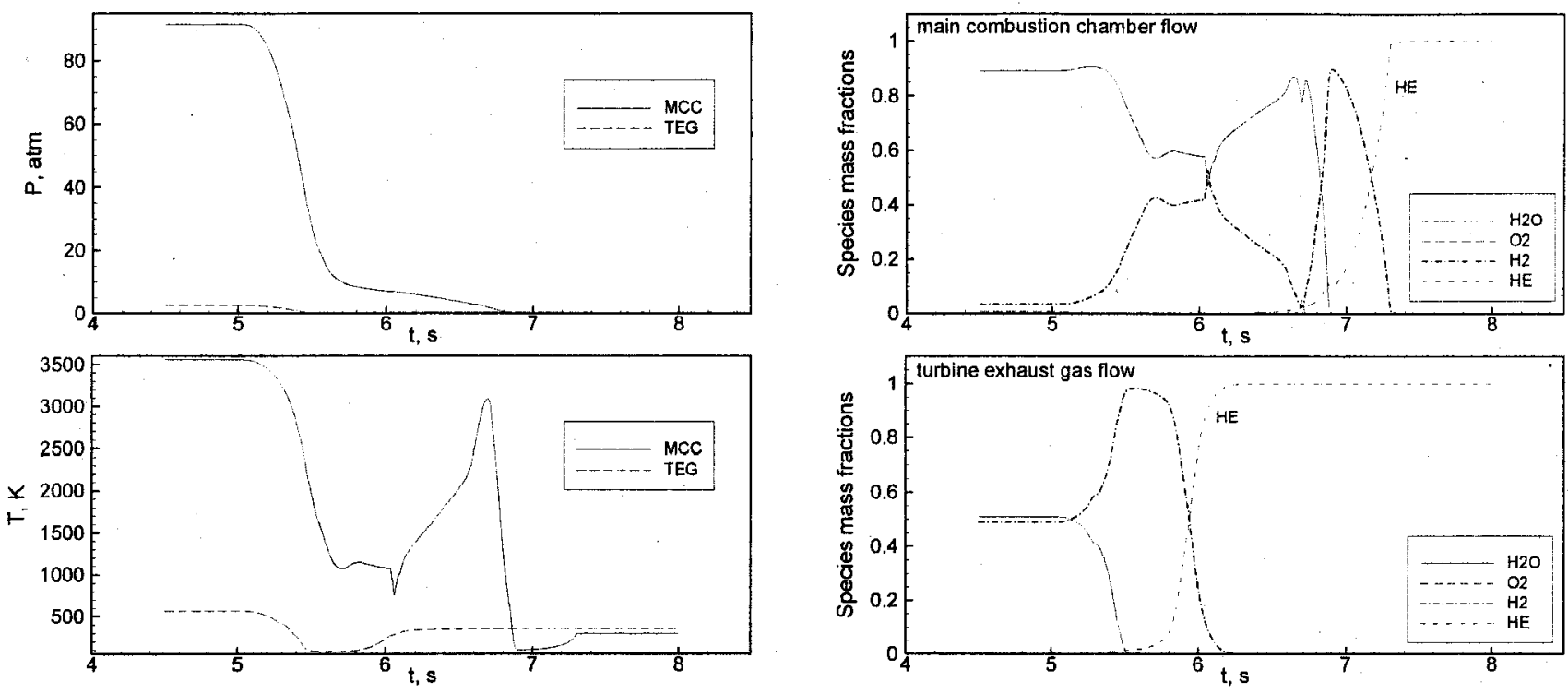

Fig. 3 Simulated inlet pressure and temperature histories for the main combustion chamber and turbine exhaust gas flows during the shutdown transient.

Fig. 4 Simulated inlet pressure and temperature histories for the main combustion chamber and turbine exhaust gas flows during the shutdown transient.

employed to provide wall boundary layer solutions that are less sensitive to the near-wall grid spacing. Consequently, the model has combined the advantages of both the integrated-to-the-wall approach and the conventional law-of-the-wall approach by incorporating a complete velocity profile and a universal temperature profile $^{14}$. A 7-species, 9-reaction detailed mechanism ${ }^{14}$ was used to describe the finite-rate, hydrogen/oxygen afterburning combustion kinetics. The seven species are $\mathrm{H}_{2}, \mathrm{O}_{2}, \mathrm{H}_{2} \mathrm{O}, \mathrm{O}, \mathrm{H}, \mathrm{OH}$, and $\mathrm{N}_{2}$.

\section{B. Simulated Startup and shutdown Sequences}


The startup and shutdown sequences are important drivers to the nozzle side load physics. The ramp rate of the pressure sequence determines the magnitude and duration of the peak side load. The temperature and species mass fraction sequences determine the severity of the combustion reactions that in turn determines the magnitude and duration of the peak side load, largely because those also determines the specific heat distribution which in run determines the shock shape which affects the side load physics. In addition, if excess fuel is dumped at certain period of time, combustion wave could resulted that adds to the severity of the side load. Figure 1 shows the inlet pressure and temperature histories, while Fig. 2 shows the inlet species mass fraction histories, for the main combustion chamber and the turbine exhaust gas (TEG) flows during the startup transient. These are obtained through system modeling which models the transient operation of a network of components and therefore the valve sequences. It can be seen from Fig. 1 that the main pressure and temperature ramping occurring between 1 and $3 \mathrm{~s}$, and from Fig. 2 that Helium (He) gas enters both the main combustion chamber and TEG flow right after the start command, this has the effect of reducing and diluting the fuel concentration and possibly

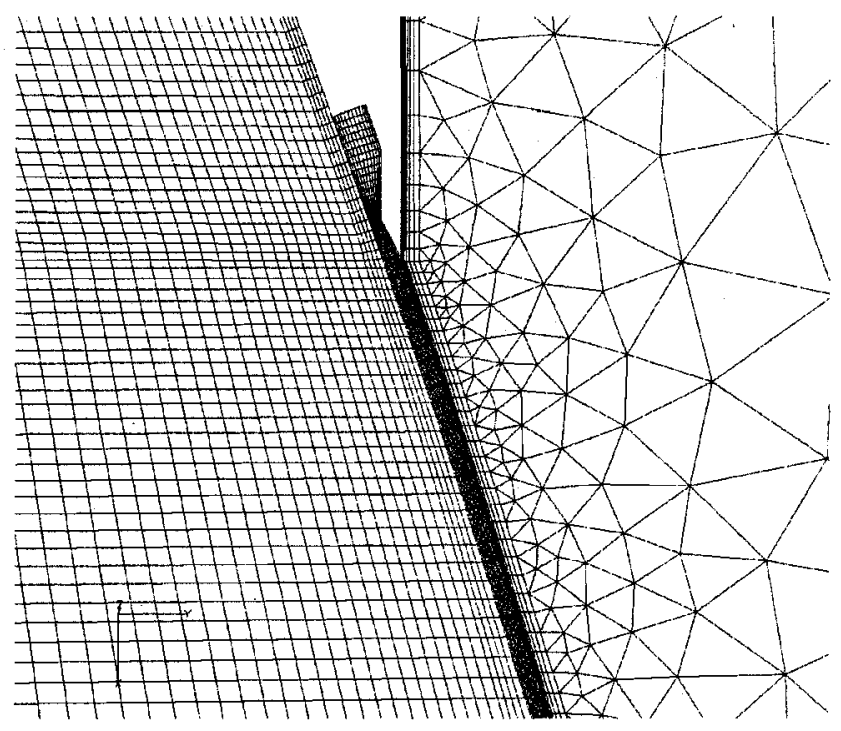

Fig. 5 A close-up look at the hybrid computational grid near the nozzlette that houses the turbine exhaust flow. eliminating the combustion wave. Figure 3 shows the simulated inlet pressure and temperature histories, while Fig. 4 shows the species mass fraction histories of the main combustion chamber and TEG flows during the shutdown transient. It can be seen from Figs. 3 that the pressure and temperature ramping down in a much shorter time period, from about 5.2 to $5.6 \mathrm{~s}$. From Fig. 4, there are again He flows near the end of the shut down transient. Also, there is a rise of hydrogen concentration from about 6.8 to $7.2 \mathrm{~s}$ in the main combustion flow and a corresponding rise in the temperature. The effect of this rise in hydrogen concentration and temperature will be examined through the computation. 


\section{Computational Grid Generation}

The computational domain for the $\mathrm{J} 2-\mathrm{X}$ nozzle side load investigation includes the combustion chamber, nozzle, nozzlette for TEG flow injection, nozzle extension, plume and ambient air regions. The nozzle and its extension combined has a truncated ideal contour, although the nozzle extension is offset from the nozzle exit by a distance of the nozzlette exit (hydraulic) diameter to allow the TEG flow coming in. Current configuration has an aspect ratio of 35 for the nozzle; and an aspect ratio of 92 for the nozzle extension. The exit of the nozzlette is flush with the nozzle exit. The nozzle is nicknamed as the "stub nozzle" when the nozzle extension is removed. The procedure for grid generation follows that of the benchmark effort for

SSME by rotating two axisymmetric grids that already passed the integrated axial force test into three threedimensional (3-D) grids, using a software package GRIDGEN. ${ }^{15}$ These three 3-D grids have grid points of $1,581,306(3 \mathrm{~d} 1) 2,011,902(3 \mathrm{~d} 2)$, and $2,148,812(3 \mathrm{~d} 3)$

were again subjected to the integrated axial force tests and grids $3 \mathrm{~d} 2$ and $3 \mathrm{~d} 3$ were selected to do the actual transient computations. Similar to the grid used in the SSME benchmark, these grids have structured-grid for the combustor, nozzle, and plume region and

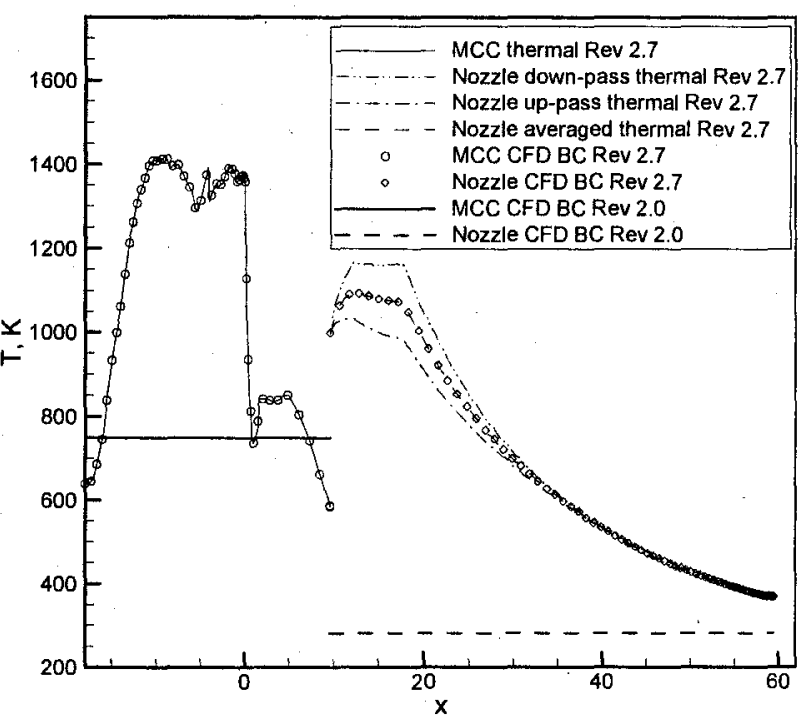
unstructured-grid for the ambient air region. This is

Fig. 6 The temperature boundary condition foe the combustion chamber and nozzle.

because not only is structured-grid a better quality grid

(for the action region), by using the structured-grid and by rotating an axisymmetric grid, the grid for the combustor and nozzle grid is symmetric to the centerline, therefore there will be no chance for asymmetric unstructured-grid induced side load. Figure 5 shows a typical layout for the computational grid. Note that there are computational grids inside the solid part of the nozzle extension for conjugate heat transfer computation. The total grid points used in these 3-D grids are higher than the 1,286,934 points used for the SSME benchmark, and much higher than the $145,500 \sim 405,900$ points used for the side load calculations for the LE-7, LE-7A, and CTP-50-R5-L engines. ${ }^{7}$ 


\section{Boundary and Inlet Conditions}

Total conditions were used for the outer boundary and four fixed total conditions were used to simulate hotfiring at four different altitudes. The inlet flow properties obtained from the system simulation include the time varying total pressure, temperature, and propellant composition. The time varying propellant composition was preprocessed with the Chemical Equilibrium Calculation program ${ }^{16}$, assuming the propellants were ignited to reach equilibrium composition immediately beyond the injector faceplate. There was speculation that the radiation from the nozzle extension wall would be significant and should be included in the transient calculations. Four separate steady-state computations were therefore performed with coupled radiation calculations for both nozzle extension solid and the gas medium water. The results show that the radiation does not affect the computed axial force for all four altitudes and was ignored for the subsequent transient side load computations. This is probably because of the cold TEG flow shielded the nozzle extension from the hot bulk flow. In addition, since the combustion chamber and nozzle are regeneratively cooled and it has been shown that the cold wall temperatures due to the regenerative cooling affected whether a free-shock separation or a restricted-shock separation persisted in the Mach disk flow, which eventually affected the magnitude of the peak side load, a separate conjugate heat transfer calculation was performed and the combustion chamber and nozzle wall temperature profiles were provided as the boundary condition, as shown in Fig. 6 . On the other hand, since the nozzle extension wall temperature is also important at the sea level, but not important at the high altitudes, coupled conjugate heat transfer for the nozzle extension was performed at sea level to provide accurate temperature boundary condition for the propagating Mach disk flow.

\section{Results and Discussion}

The computations were performed on a cluster machine using 16 processors. Global time steps were varied throughout the computations: $2.5 \sim 10 \mu$ s were typically used during the initial transient when the change of flow physics was mild, and 1 2.5 $\mu$ s were used when strong flow physics such as combustion, shock transitions and shock oscillations across the lip were occurring. It was known to the design engineers that nozzle side load will be large at a nozzle aspect ratio of 92 for sea level testing. Hence, only the side loads at altitudes of $61 \mathrm{k}, 75 \mathrm{k}$, and $100 \mathrm{k}$ $\mathrm{ft}$, and those for the stub nozzle at sea level are of interest. The case for full nozzle extension at sea level was added for demonstration and as for reference purposes. The results of the startup transients at the four altitudes (including 
the reference sea level case) are presented first, followed by the results of the startup and shutdown transients for the stub nozzle.

\section{A. Startup transients with nozzle extension at four altitudes}
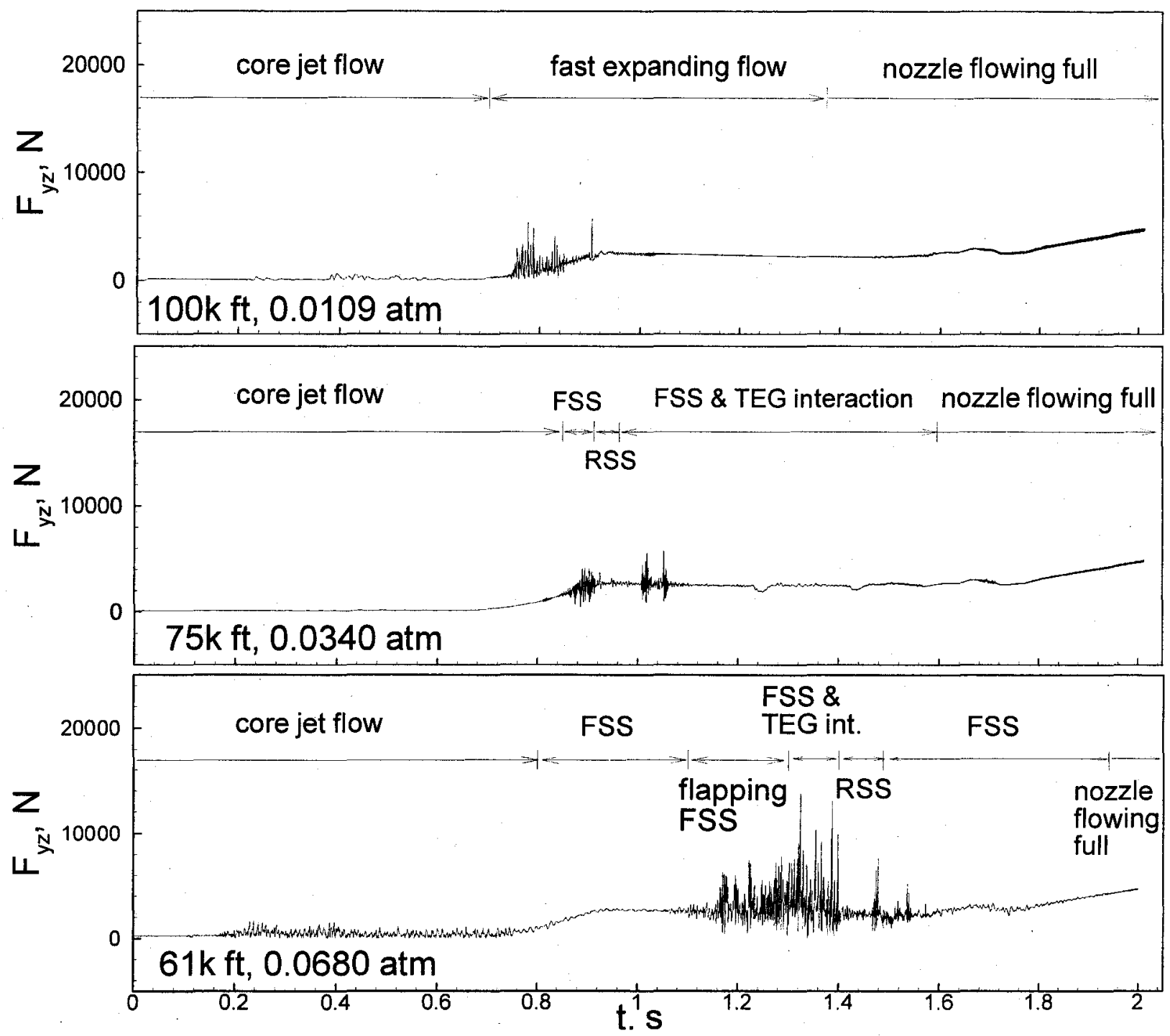

Fig. 7 Computed side force histories during startup at three high altitudes. 
Figure 7 shows the computed side load histories for the startup transients at altitudes of $61 \mathrm{k}, 75 \mathrm{k}$, and $100 \mathrm{k} \mathrm{ft}$. At $61 \mathrm{k} \mathrm{ft}$, the exhaust plume started out as a core jet flow. It changes to a FSS Mach disk flow around $0.8 \mathrm{~s}$, then the supersonic jet of the Mach disk flow starts to flap after $1.1 \mathrm{~s}$ and the side load increases. After $1.32 \mathrm{~s}$, the supersonic jet of the Mach disk flow interacted with the TEG flow and a peak side load occurring around $1.34 \mathrm{~s}$. After about 1.4 $\mathrm{s}$, the FSS transforms into a RSS. The RSS switches back to FSS at about $1.5 \mathrm{~s}$ and the nozzle flow full at about 1.94 s. At $75 \mathrm{k} \mathrm{ft}$, the core jet flow changes into FSS Mach disk flow at around $0.85 \mathrm{~s}$, transforms itself into RSS Mach

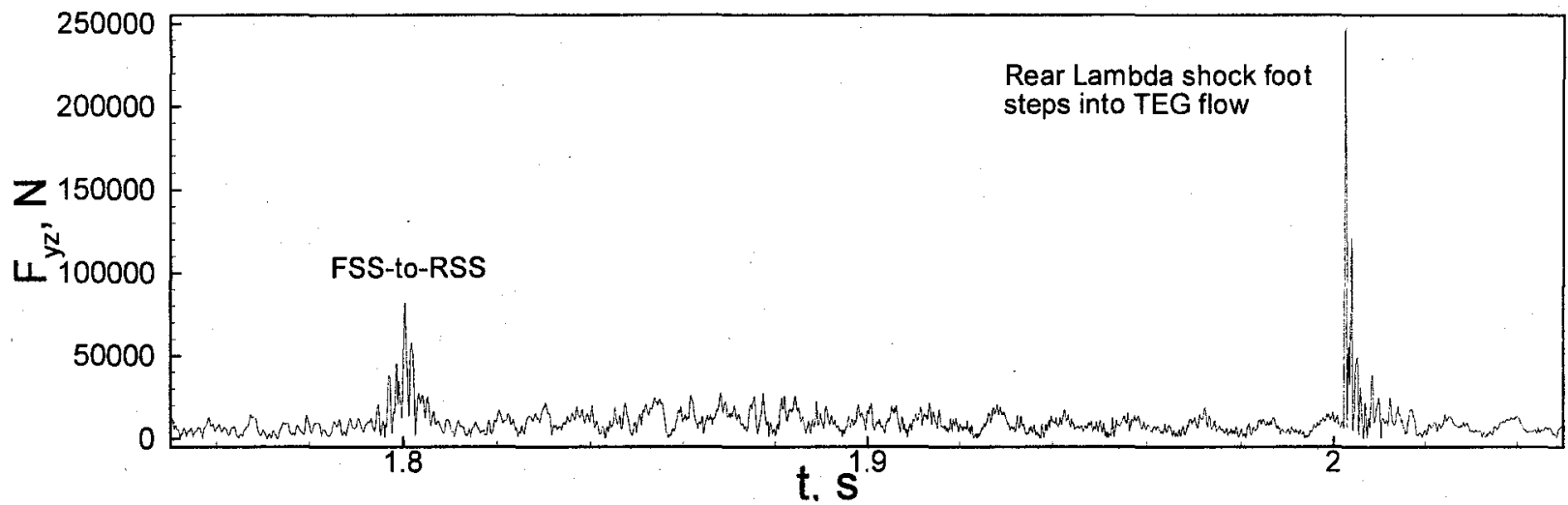

Fig. 8 Computed side force history during startup at sea level.

disk flow after $0.9 \mathrm{~s}$, which then switches back to FSS quickly around $0.95 \mathrm{~s}$. The supersonic jet of the FSS then interacts with the TEG flow and produced a peak side load at about $1.01 \mathrm{~s}$ and a secondary peak at about $1.05 \mathrm{~s}$. The nozzle flows full at about $1.62 \mathrm{~s}$. At $100 \mathrm{k} \mathrm{ft}$, due to the now very low ambient pressure, the core jet flow expands

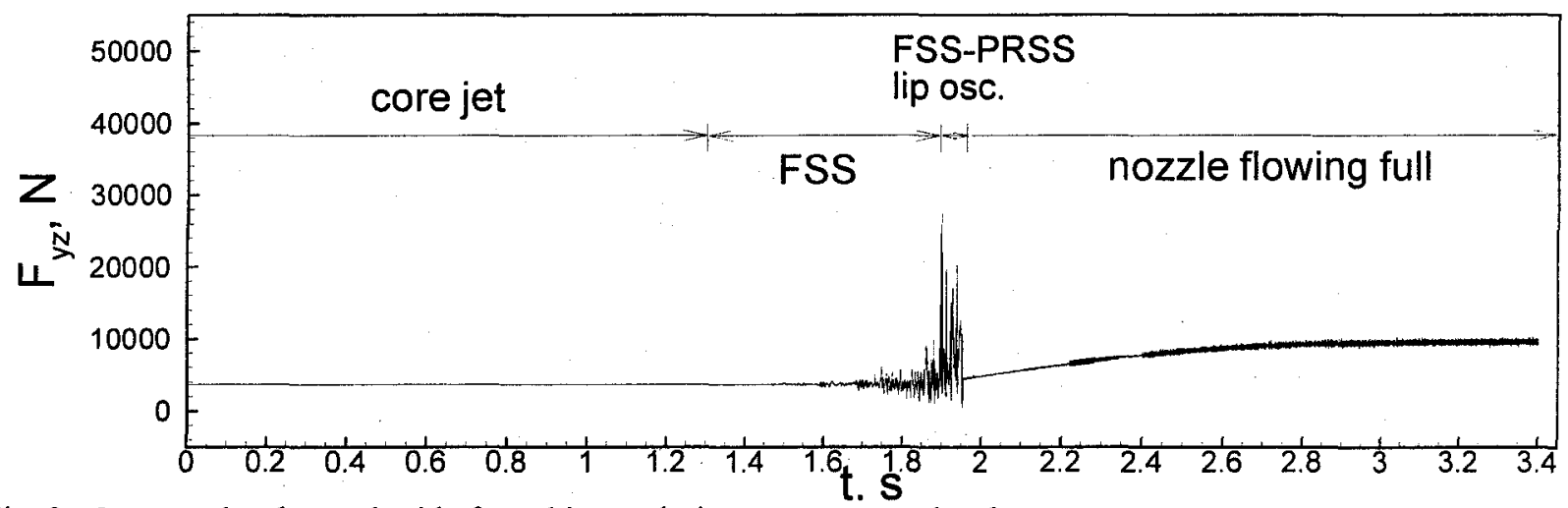

Fig. 9 Computed stub nozzle side force history during startup at sea level.

quickly into a fast expanding flow around $0.7 \mathrm{~s}$, generating a peak side load around $0.9 \mathrm{~s}$, and flows full quickly at about $1.35 \mathrm{~s}$. It can be seen that the peak side loads decrease as the altitudes increase, and the time for nozzle flowing full decreases as the altitude increases. 
Figure 8 shows the computed side load history at sea level. It can be seen that there are two distinctive side load physics that produce much larger side loads then any of those at high altitudes: the FSS-to-RSS transition that produces the secondary peak side load at around $1.8 \mathrm{~s}$, and the rear Lambda shock foot of the RSS stepping into the TEG flow that generates the very large peak side load at around $2.1 \mathrm{~s}$. The effect of air density on the side load physics is obvious in here. Note that because of aspect ratio is so large in here and the chamber pressure is not large enough to push the Mach disk out of the lip, the case is never flowing full. As a result, the side load physics of shock oscillation across the lip that generated the peak side load for SSME was not occurring in this case.

\section{B. Startup and shutdown transients of stub nozzle at sea level}

The large side load occurring in the theoretical case shown in Fig. 8 is the reason why the side load of a stub nozzle is of more interest. Figure 9 shows the computed side load history for the stub nozzle during startup transient at sea level. It can be seen that the core jet turns into a FSS Mach disk flow at around $1.3 \mathrm{~s}$. While the FSS-to-RSS occurs at the $1.8 \mathrm{~s}$ for the full nozzle case, the shortness and the low aspect ratio of the stub nozzle make that shock transition difficult. In fact, only FSS-to-partial RSS (PRSS) occurring at around $1.9 \mathrm{~s}$ and simultaneously the PRSS reaches the lip and oscillates several times and leaves the nozzle. These physics create a peak side load of about 30 $\mathrm{kN}$ which is much less than that of $80 \mathrm{kN}$ when the nozzle extension is attached. The peak side load occurring $\mathbf{n}$ Fig. 8 when the rear foot of the lambda stepping over the TEG flow was never occurring because the Mach disk is out of the nozzle very quickly around $1.95 \mathrm{~s}$, even though the TEG flow was still on but it was not constrained by a nozzle

extension. This demonstrates that even for a truncated ideal nozzle, for FSS-to-RSS to happen, the nozzle has to be long enough, and aspect ratio has to be large enough, and the wall temperature has to be cold enough. 


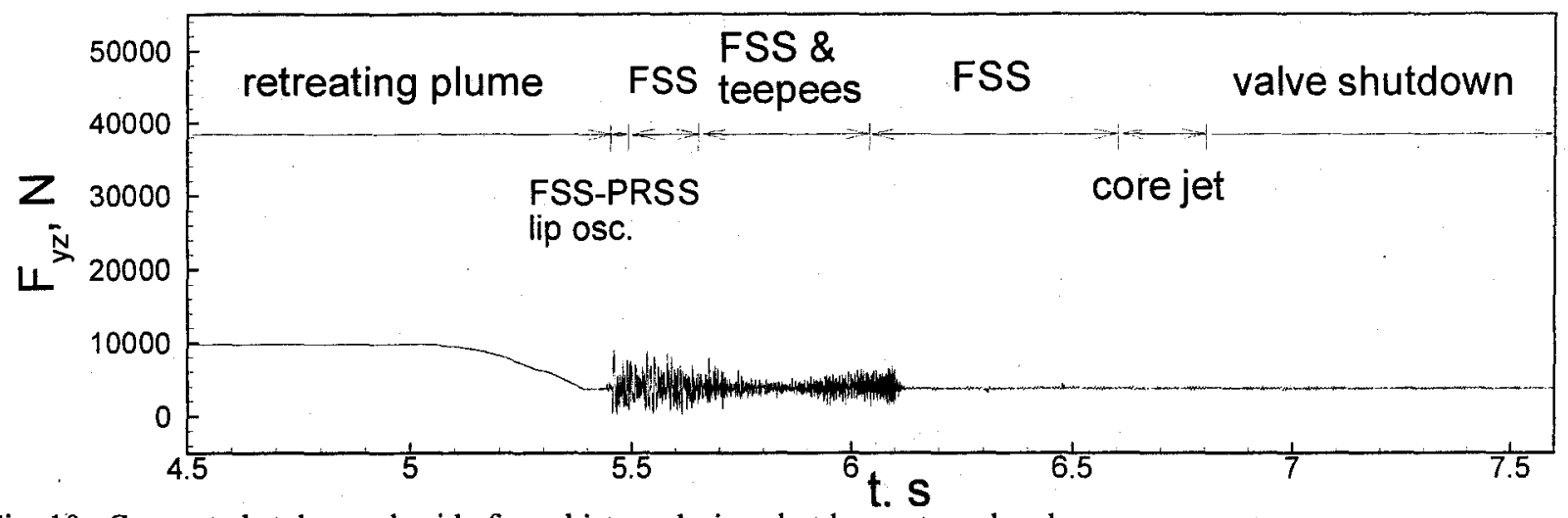

Fig. 10 Computed stub nozzle side force history during shutdown at sea level.

Figure 10 shows the computed side force history for the stub nozzle during shutdown at sea level. As described in Fig. 10, after $5.4 \mathrm{~s}$ into the shutdown transient, the Mach disk of the plume retreats to the lip level and oscillates across the lip as FSS and PRSS, then the retreating Mach disk wave quickly becomes FSS at $5.5 \mathrm{~s}$. Between 5.5 and $6.1 \mathrm{~s}$, teepees form on the inside of the nozzle wall. This is because the composition of the TEG becomes pure hydrogen, and the counterflowing TEG jet and the entrained air reacted to form several triangular shaped formations on the nozzle wall. The triangular formation starts as one and gradually increases to around five or so, and then its numbers decrease and finally disappears around $6.1 \mathrm{~s}$. The timing of the appearance and disappearance of the teepees matches that of the hydrogen mass fraction reaching 1.0 and its decreases to zero, as shown in the TEG composition history in Fig. 4. The side load increases starting from the FSS-to-PRSS and lip oscillation events drops to nil as the teepees disappear, although the peak side load level is insignificant. This is all attributed to the short nozzle and the low aspect ratio, and the fast down ramping rate. It is also noted that the high hydrogen mass fraction and high temperature in the core flow around $7 \mathrm{~s}$, as shown in Figs. 3 and 4, contributed nothing to side load because the valve essentially shuts down after $6.8 \mathrm{~s}$.

\section{Conclusions}

Three-dimensional numerical investigations on the nozzle side load have been performed for a preliminary version of the $\mathrm{J} 2-\mathrm{X}$ engine. It is shown that the peak side loads computed for startup operation at high altitudes are manageable and are decreasing with altitudes. The computed peak side load for startup at a theoretical testing case at sea level is large and caused by the rear foot of the Lambda shock stepping into the TEG flow. For the stub nozzle operating at sea level, the computed peak side load of startup transient is small because of the short nozzle and low 
aspect ratio; the computed peak side load of shutdown transient is even smaller for the same reason, and further more, for the fast ramp down time. Teepee formations were captured during the shutdown transient, and those are caused by the combustion of the counterflowing excess hydrogen TEG jet and the entrained air.

\section{Acknowledgments}

This study was partially supported by a MSFC J2-X nozzle side load task. The lead author wishes to thank Paul Gradl and Warren Peters for their support of the task, Joe Ruf for providing the thruster geometry, and Van Luong for providing the combustion chamber and nozzle wall temperatures as boundary conditions. Special thanks is given to James Beck of Pratt-Whitney Rocketdyne for his insightful suggestions and discussions.

\section{References}

'Nave, L.H., and Coffey, G.A., "Sea Level Side Loads in High-Area-Ratio Rocket Engines," AIAA Paper 73-1284, Nov. 1973.

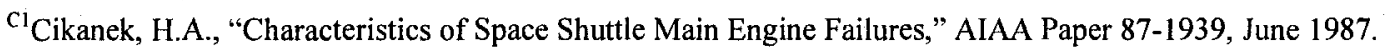

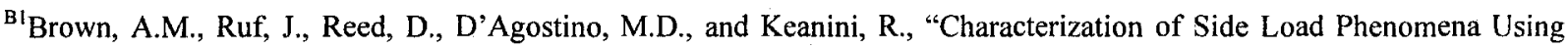
Measurement of Fluid/Structure Interaction," AIAA Paper 2002-3999, July 2002.

${ }^{\text {H1} H a g e m a n n, ~ G ., ~ T e r h a r d t, ~ M ., ~ F r e y, ~ M ., ~ R e i j a s s e, ~ P ., ~ O n o f r i, ~ M ., ~ N a s u t i, ~ F ., ~ a n d ~ O s t l u n d, ~ J ., ~ " F l o w ~ S e p a r a t i o n ~ a n d ~ S i d e-~}$ Loads in Rocket Nozzles," $4^{\text {th }}$ International Symposium on Liquid Space Propulsion, March 12-15, 2000, DLR Lampoldshausen.

${ }^{2}$ Hageman, G., Alting, J., and Preclik, D., "Scalability for Rocket Nozzle Flows Based on Subscale and Full-Scale Testing," Journal of Propulsion and Power, Vol. 19, No. 3, 2003, pp.321-331.

${ }^{3}$ Wantabe, Y., Sakazume, N., and Tsuboi, M., "LE-7A Engine Nozzle Problems During the Transient Operations," AIAA Paper 2002-3841, July 2002 .

${ }^{4}$ Wang, T.-S., "Numerical Study of the Transient Nozzle Flow Separation of Liquid Rocket Engines," Computational Fluid Dynamics Journal, Vol. 1, No. 3, 1992, pp. 319-328.

${ }^{5}$ Chen, C.L., Chakravathy, S.R., and Hung, C.M., "Numerical Investigation of Separated Flows," AIAA Journal, Vol. 32, No. 9, 1994, pp. 1836-1843. 
${ }^{6}$ Yonezawa, K., Yokota, K., Watanabe, Y., Tsujimoto, K., and Abe, T., "2-D Numerical Simulation of Side Loads in Rocket Nozzles," Proceedings of $23^{\text {rd. }}$ International Symposium on Space Technology and Science, Japan Society for Aeronautical and Space Sciences, 2002, pp. 1146-1151.

${ }^{7}$ Yonezawa, K., Yokota, K., Tsujimoto, K., Sakazume, N., and Watanabe, Y., "Three-Dimensional Unsteady Flow Simulation of Compressed Truncated Perfect nozzles," AIAA Paper 2002-3991, July 2002.

${ }^{8}$ Wang, T.-S., "Transient Two-Dimensional Analysis of Side Load in Liquid Rocket Engine Nozzles," AIAA Paper 20043680, 11-14 July, 2004.

${ }^{9}$ Wang, T.-S., "Multidimensional Unstructured-Grid Liquid Rocket Engine Nozzle Performance and Heat Transfer Analysis," Journal of Propulsion and Power, Vol. 22, No. 1, January-February, 2006, pp. 78-84.

${ }^{10}$ Chen, Y.-S., Liu, J., Zhang, S., and Mallapragada, P., "An Integrated Tool for Launch Vehicle Base-Heating Analysis," Final Report, Engineering Sciences, Inc., Huntsville, AL, December 2001.

${ }^{11}$ Wang, T.-S., Chen, Y.-S., Liu, J., Myrabo, L.N., and Mead, F.B. Jr., "Advanced Performance Modeling of Experimental Laser Lightcraft," Journal of Propulsion and Power, Vol. 18, No. 6, 2002, pp. 1129-1138.

${ }^{12}$ Chen. Y.-S., Zhang S., and Liu, J., "Stage Separation Performance Analysis Project," Final Report, Engineering Sciences, Inc., Huntsville, AL, June, 2002.

${ }^{13}$ Chen, Y.-S., and Kim, S. W., "Computation of Turbulent Flows Using an Extended k- $\varepsilon$ Turbulence Closure Model," NASA CR-179204, Oct. 1987.

${ }^{14}$ Wang, T.-S., Droege, A., D'Agostino, M., Lee, Y.-C., and Williams, R., "Asymmetric Base-Bleed Effect on X-33 Aerospike Plume Induced Base-Heating Environment," Journal of Propulsion and Power, Vol. 20, No. 3, 2004, pp. $385-393$.

${ }^{15}$ Steinbrenner, J.P., Chawner, J.R., and Fouts, C., "Multiple Block Grid Generation in the interactive Environment," AIAA Paper 90-1602, June 1990.

${ }^{16}$ Svehla, R.A., and McBride, B.J., "FORTRAN IV Computer Program for Calculation of Thermodynamic and Transport Properties of Complex Chemical Systems," NASA TN D-7056, Jan. 1973.

${ }^{17}$ Kumada, M., Mabuchi, I., and Oyakawa, K., "Studies on Heat Transfer to Turbulent Jets with Adjacent Boundaries," Bulletin of the Japan Society of Mechanical Engineers, Vol. 16, No. 100, 1973, pp. 1712-1722.

${ }^{18}$ Chang, C.L., Kronzon, Y., and Merkle, C.L., "Time-Iterative Solutions of Viscous Supersonic Nozzle Flows," AIAA Journal, Vol. 26, No. 10, 1988, pp. 1208-1215.

${ }^{19}$ Shimura K., Asako, Y., and Lee, J.H., "Numerical Analysis for Supersonic Flows in a Cooled Nozzle," Numerical Heat Transfer, Part A., Vol. 26, 1994, pp.631-641.

${ }^{20}$ Watanabe, Y., Sakazume, N., Yonezawa, K., and Tsujimoto, Y., "LE-7A Engine Nozzle Flow Separation Phenomenon and the Possibility of RSS Suppression by the Step inside the Nozzle," AIAA Paper 2004-4014, 11-14 July, 2004. 
${ }^{21}$ Larson, E.W., Ratekin, G.H., and O’Connon, G.M., "Structural Response to the SSME Fuel Feedline to Unsteady Shock Oscillations," Part 2, Bulletin 52, The Shock and Vibration Bulletin, May 1982, pp. 177-182. 